\title{
Redução de proteína e fósforo em dietas com fitase para frangos de corte dos 22 aos 42 dias de idade
}

\author{
[Reduction of protein and phosphorus in diets containing phytase for \\ broilers from 22 to 42 days of age] \\ Y.L. Silva ${ }^{1}$, P.B. Rodrigues ${ }^{2 *}$, M.G. Zangeronimo ${ }^{2}$, E.T. Fialho ${ }^{2}$, \\ R.T.F. de Freitas $^{2}$, R.R. Alvarenga ${ }^{2}$ \\ ${ }^{1}$ Universidade Estadual do Oeste do Paraná - UNIOESTE, PR \\ ${ }^{2}$ Universidade Federal de Lavras - Lavras, MG
}

\begin{abstract}
RESUMO
Avaliou-se o efeito da inclusão de fitase em dietas com proteína bruta (PB) e fósforo disponível (Pd) reduzidos sobre o desempenho, rendimento de carcaça e cortes e quantidade de poluentes na cama de frangos dos 22 aos 42 dias de idade. Foram utilizados 1200 pintos aos 21 dias, média de peso inicial de $646 \pm 8 \mathrm{~g}$, distribuídos em blocos ao acaso em esquema fatorial $3 \times 3+1$ (três porcentagens de $\mathrm{Pd}-0,2,0,3 \mathrm{e}$ $0,4 \%$ - e três de PB - 14, 16 e $18 \%$ - e um tratamento adicional, padrão) em seis repetições de 20 aves cada. A fitase (500FTU/kg) foi adicionada nas dietas com fósforo reduzido (0,2 e 0,3\%). Aos 42 dias as aves foram abatidas e amostras das camas foram encaminhadas para análise. Em dietas com reduzido teor de $\mathrm{PB}$, melhor desempenho e rendimento de carcaça e menor quantidade de fósforo, cálcio, potássio e zinco nas camas foram obtidos com $0,3 \% \mathrm{Pd}+$ fitase. Menor quantidade de nitrogênio e potássio, porém com maior deposição de gordura abdominal e maior excreção de cobre, foram obtido com 14\% de PB. Comparadas ao controle, dietas com $14 \%$ de PB e $0,3 \%$ de Pd reduziram a excreção de fósforo em $34 \%$. Conclui-se que dietas com $14 \%$ de PB e $0,3 \%$ de Pd, suplementadas com fitase e aminoácidos cristalinos, podem ser utilizadas para frangos de corte dos 22 aos 42 dias.
\end{abstract}

Palavras-chave: frango de corte, carcaça, contaminação do ambiente, desempenho, proteína ideal

\begin{abstract}
The effect of the inclusion of phytase in reduced crude protein $(C P)$ and available phosphorus (aP) diets on performance, carcass and cut yields and the amount of pollutant elements in the litter of broilers from 22 to 42 days of age was evaluated. One thousand and two hundred male broilers at 21 days of age, initial weight of $646 \pm 8 g$, were distributed in randomized block design in factorial scheme $3 \times 3+1$ (three levels of aP-0.2, 0.3 and $0.4 \%$ - and three of $C P-14,16$ and $18 \%$ - and an additional treatment, standard) in six repetitions of 20 birds each. Phytase (500 FTU/kg) was added in reduced phosphorus $(0.2$ and $0.3 \%)$ diets. At 42 days of age, the birds were sacrificed and samples of the litters were sent to the laboratory for analysis. In reduced-CP diets, the best performance and carcass yield and lesser quantity of phosphorus, calcium, potassium and zinc in the litter was obtained with $0.3 \%$ aP + phytase diets. The minor quantity of nitrogen and potassium in the litter, with higher abdominal fat deposition and excretion of cupper were obtained with 14\% CP diets. Compared to control, diets with $14 \%$ CP and $0.3 \%$ aP reduced the excretion of phosphorus in $34 \%$. It was concluded that diets with $14 \%$ CP and $0.3 \%$ $a P$, supplemented with phytase and crystalline amino acids, can be used in broilers from 22 to 42 days old.
\end{abstract}

Keywords: avian production, carcass, contamination of environment, ideal protein, performance

Recebido em 23 de julho de 2010

Aceito em 3 de novembro de 2011

*Autor para correspondência (corresponding author)

E-mail:pborges@dzo.ufla.br

Projeto financiado pelo $\mathrm{CNPq}$

Apoio: FAPEMIG 


\section{INTRODUÇÃO}

Para reduzir a contaminação ambiental por elementos presentes na excreta de aves, o tratamento e o destino adequado desse material têm preocupado técnicos, produtores e pesquisadores, que buscam soluções para evitar o impacto ambiental desses resíduos. Nesse sentido, algumas alternativas têm sido preconizadas, tais como: o uso de dietas melhor balanceadas ou a inclusão de aditivos que melhorem o aproveitamento de nutrientes pelas aves.

A redução da proteína bruta e a suplementação de dietas com os aminoácidos cristalinos têm permitido atender melhor às exigências aminoacídicas das aves, reduzindo, dessa forma, a eliminação de nitrogênio em excesso na excreta. No entanto, o uso desse conceito tem sido atribuído à maior deposição de gordura na carcaça das aves e ao menor rendimento de cortes (Faria Filho et al., 2005).

Outro aspecto que tem sido considerado para atender à necessidade de reduzir a excreção de poluentes pelas aves é a adição de enzimas exógenas nas dietas, como exemplo, a fitase, cuja utilização tem possibilitado maior aproveitamento de nutrientes, principalmente o fósforo, devido à hidrólise total ou parcial do ácido fítico presente em alimentos de origem vegetal. Segundo Sebastian et al. (1998), a molécula de ácido fítico tem a capacidade de reduzir a atividade da pepsina, tripsina e amilase, devido à ligação às proteínas presentes nos alimentos. Com isso, espera-se melhorar o aproveitamento desses nutrientes, por meio da quebra desses fatores antinutricionais, pela utilização de fitase microbiana nas dietas. Além disso, outros nutrientes podem também ser disponibilizados, tais como o zinco e o cobre, reduzindo $o$ impacto ambiental potencial provocado pela excreção destes elementos (Biehl et al., 1995).

A associação entre a aplicação do conceito de proteína ideal e a inclusão de fitase em diferentes níveis de proteína bruta e fósforo disponível em dietas para frangos de corte em crescimento tem sido pouco estudada. $\mathrm{O}$ objetivo deste trabalho foi avaliar o desempenho e os teores de elementos poluentes na cama, bem como o rendimento de carcaça e cortes de frangos de corte alimentados nessas condições dos 22 aos 42 dias de idade.

\section{MATERIAL E MÉTODOS}

Foram utilizados 1.200 pintos de corte machos Cobb dos 21 aos 42 dias de idade, com peso inicial de 646 $8 \mathrm{~g}$, distribuídos em galpão de alvenaria em boxes $(1,50 \times 2,00 \mathrm{~m})$ com piso forrado com maravalha, todos com comedouro tubular e um bebedouro pendular. Previamente ao período experimental, as aves foram mantidas em condições homogêneas, criadas a partir de um dia de vida. Água e dieta foram fornecidas à vontade durante o período experimental, mantendo sempre 24 horas de luz no galpão. As temperaturas máximas e mínimas no interior do galpão foram mensuradas diariamente, obtendose os valores de $27,1 \pm 2,0$ e $16,1 \pm 2,7^{\circ} \mathrm{C}$, respectivamente. As camas foram constituídas por maravalha e distribuídas de forma homogênea entre as parcelas experimentais no início do experimento.

O delineamento experimental foi em blocos ao acaso (disposição dos boxes no galpão) em esquema fatorial $3 \times 3+1$ (três porcentagens de fósforo disponível - 0,2, 0,3 e $0,4 \%$ - e três de proteína bruta - 14, 16 e $18 \%$ - e um tratamento adicional), totalizando 10 tratamentos com seis repetições de 20 aves cada. O tratamento adicional foi constituído por uma dieta-controle, formulada de acordo com as recomendações de Rostagno et al. (2000), para esta idade.

As dietas foram formuladas com milho e farelo de soja baseando-se nos valores de aminoácidos digestíveis dos alimentos, mantendo-se a relação ideal desses nutrientes com a lisina. Em dietas com 0,2 e $0,3 \%$ de fósforo disponível, foram adicionados 500FTU de fitase/kg (Ronozyme 2500FTU/g), reduzindo-se o cálcio de 0,87 para $0,70 \%$, segundo recomendação de Schoulten (2001). As composições das dietas experimentais estão apresentadas na Tab. 1.

Ao final do período experimental, os animais foram submetidos a jejum de oito horas e, após esse período, foram pesados para obtenção do peso final. As sobras de dieta foram registradas para obtenção do consumo. Em seguida, duas aves de cada parcela foram retiradas de forma aleatória e abatidas por deslocamento cervical seguido de sangria na artéria carótida. Após a 
retirada das penas, os animais foram eviscerados, e as carcaças (sem cabeça, pés e gordura abdominal - gordura depositada na região abdominal, próxima à Bursa de Fabricius e à cloaca) foram, então, pesadas. $\mathrm{O}$ peito, as sobrecoxas, o dorso e as asas foram individualmente pesados, além da gordura abdominal, para a determinação dos rendimentos de cortes. Para os cálculos, foram consideradas as médias das duas aves. O rendimento de carcaça foi calculado por meio da relação peso da carcaça eviscerada, sem cabeça, e o peso vivo das aves e os rendimentos dos cortes e gordura abdominal em relação ao peso da carcaça eviscerada.

Tabela 1. Ingredientes e composição química das dietas experimentais

\begin{tabular}{|c|c|c|c|c|}
\hline \multirow{4}{*}{ Ingrediente $(\%)$} & \multicolumn{4}{|c|}{ Proteína bruta $(\%)$} \\
\hline & 19 & 14 & 16 & 18 \\
\hline & \multicolumn{4}{|c|}{ Fósforo disponível (\%) } \\
\hline & 0.4 & $0,2 / 0,3 / 0,4$ & $0,2 / 0,3 / 0,4$ & $0,2 / 0,3 / 0,4$ \\
\hline Milho & 61,5 & 75,6 & 70,3 & 65,0 \\
\hline Farelo de soja & 30,5 & 16,4 & 21,8 & 27,1 \\
\hline Óleo de soja & 3,83 & 2,05 & 2,70 & 3,39 \\
\hline Fosfato bicálcico & 1,70 & $0,66 / 1,30 / 1,81$ & $0,61 / 1,17 / 1,72$ & $0,61 / 1,16 / 1,72$ \\
\hline Calcário & 1,00 & $1,27 / 0,88 / 1,05$ & $1,27 / 0,94 / 1,08$ & $1,22 / 0,88 / 1,02$ \\
\hline L-Lisina $\mathrm{HCl} 78 \%$ & 0,180 & 0,610 & 0,450 & 0,300 \\
\hline DL-Metionina & 0,200 & 0,330 & 0,280 & 0,240 \\
\hline L-Valina & - & 0,280 & 0,200 & 0,110 \\
\hline L-Arginina & - & 0,360 & 0,210 & 0,050 \\
\hline L-Treonina & - & 0,130 & 0,070 & - \\
\hline L-Isoleucina & - & 0,210 & 0,120 & 0,020 \\
\hline L- Triptofano & - & 0,050 & - & - \\
\hline L-Fenilalanina & - & 0,060 & - & - \\
\hline Sal & 0,400 & 0,400 & 0,400 & 0,400 \\
\hline Suplemento mineral ${ }^{1}$ & 0,050 & 0,050 & 0,050 & 0,050 \\
\hline Suplemento vitamínico ${ }^{2}$ & 0,100 & 0,100 & 0,100 & 0,100 \\
\hline Colina & 0,050 & 0,050 & 0,050 & 0,050 \\
\hline Coban $400^{3}$ & 0,030 & 0,030 & 0,030 & 0,030 \\
\hline Etoxiquin $(125 \mathrm{mg} / \mathrm{kg})$ & 0,010 & 0,010 & 0,010 & 0,010 \\
\hline Fitase & - & $0,02 / 0,02 /--$ & $0,02 / 0,02 /--$ & $0,02 / 0,02 /--$ \\
\hline Caulim & 0,450 & $1,33 / 1,08 / 0,42$ & $1,35 / 1,12 / 0,45$ & $1,40 / 1,19 / 0,51$ \\
\hline \multicolumn{5}{|l|}{ Composição calculada } \\
\hline Proteína bruta $(\%)$ & 19 & 14 & 16 & 18 \\
\hline Energia metabolizável (kcal/kg) & 3100 & 3100 & 3100 & 3100 \\
\hline Fósforo disponível (\%) & 0,4 & $0,2 / 0,3 / 0,4$ & $0,2 / 0,3 / 0,4$ & $0,2 / 0,3 / 0,4$ \\
\hline Cálcio $(\%)$ & 0,87 & $0,7 / 0,7 / 0,87$ & $0,7 / 0,7 / 0,87$ & $0,7 / 0,7 / 0,87$ \\
\hline Lisina digestível (\%) & 1,04 & 1,04 & 1,04 & 1,04 \\
\hline Metionina+cistina digestível $(\%)$ & 0,74 & 0,76 & 0,76 & 0,76 \\
\hline Arginina digestível (\%) & 1,18 & 1,14 & 1,14 & 1,14 \\
\hline Treonina digestível (\%) & 0,65 & 0,59 & 0,59 & 0,59 \\
\hline Triptofano digestível (\%) & 0,21 & 0,19 & 0,19 & 0,19 \\
\hline Valina digestível $(\%)$ & 0,85 & 0,85 & 0,85 & 0,85 \\
\hline Isoleucina digestível (\%) & 0,74 & 0,71 & 0,71 & 0,71 \\
\hline Fenilalanina digestível (\%) & 0,86 & 0,68 & 0,71 & 0,80 \\
\hline
\end{tabular}

${ }^{\mathrm{T}}$ Fornecido, por quilo de dieta: cobre 30,0mg; Zn 60,0mg; I 1,9mg; Fe 100,0mg; Mn 70,0mg.

${ }^{2}$ Fornecido, por quilo de dieta: vit. A 12.000 U.I.; vit. $\mathrm{D}_{3}$ 2.200.000U.I.; vit. E 20,0mg; vit. $\mathrm{K}_{3} 2,5 \mathrm{mg}$; vit. $\mathrm{B}_{1}$ 1,0mg; vit. $\mathrm{B}_{2} 4,0 \mathrm{mg}$; vitamina $\mathrm{B}_{6} 2,0 \mathrm{mg}$; vit. $\mathrm{B}_{12}, 20,0 \mathrm{mcg}$; niacina 25,0mg; ácido pantotênico 10,0mg; biotina 5,0mg; ácido fólico $60,0 \mathrm{mg}$; vit. C 50,0mg; antioxidante, $125,0 \mathrm{mg}$.

${ }^{3}$ Monensina $40 \%$. 
Após o abate das aves, as camas de todos os boxes foram misturadas individualmente. Em seguida, amostras aleatórias foram retiradas e submetidas à secagem em estufas de circulação de ar a $55^{\circ} \mathrm{C}$ até peso constante, após o que foram moídas para as análises laboratoriais. O teor de nitrogênio foi determinado pelo método de Kjedhal. Para os teores de fósforo, cálcio, potássio, zinco e cobre, as amostras foram submetidas à digestão nitroperclórica. Os teores de cálcio, zinco e cobre foram determinados por absorção atômica, e o de potássio e fósforo pelo fotômetro de chama e pela técnica de colorimetria.

Foram avaliados o desempenho - ganho de peso médio diário, consumo de dieta médio diário e conversão alimentar -, os rendimentos de carcaça e de cortes - coxas + sobrecoxas, peito e asas - e os teores de minerais na cama nitrogênio, fósforo, cálcio, potássio, zinco e cobre. Inicialmente, foi realizada uma análise de variância global, com todos os tratamentos, com o objetivo de obter o quadrado médio do resíduo para testar o fatorial e para realizar o teste de Dunnet a 5\%, comparando o tratamento-controle com cada um dos demais tratamentos. Como algumas dietas foram suplementadas com fitase e outras não, os tratamentos foram constituídos de combinação nutricional, tornando-se qualitativos. Neste caso, para a comparação dos tratamentos no esquema fatorial, utilizou-se o teste SNK a $5 \%$ de probabilidade. Todas as análises foram realizadas utilizando-se o pacote computacional SAEG (UFV, 1993).

\section{RESULTADOS E DISCUSSÃO}

A redução de proteína bruta nas dietas e a manutenção ou redução das porcentagens de fósforo nas dietas com fitase não influenciaram $(\mathrm{P}>0,05)$ o consumo em relação à dieta controle para frangos dos 22 aos 42 dias (Tab. 2). No entanto, houve redução no ganho de peso quando as porcentagens de proteína e fósforo foram reduzidas de forma excessiva, $14 \mathrm{e}$ $0,2 \%$, respectivamente, o que refletiu em pior conversão alimentar também em relação à dietacontrole. Estes resultados mostram que a redução excessiva de nutrientes em dieta contendo fitase e mesmo aminoácidos cristalinos pode prejudicar o desempenho das aves, nesta fase. No entanto, o aumento da conversão alimentar em dietas com
$16 \%$ de proteína bruta, sem fitase, não era esperado.

Ainda com relação ao desempenho, e considerando-se os tratamentos do esquema fatorial e dietas com reduzido teor de proteína bruta em diferentes porcentagens de fósforo com ou sem fitase, verificou-se que não houve interação $(\mathrm{P}>0,05)$. A redução do fósforo disponível de 0,4 para $0,3 \%$ com inclusão de fitase em dietas com proteína bruta reduzida resultou em maior $(\mathrm{P}<0,05)$ ganho de peso e menor conversão alimentar, porém, quando se reduziu a quantidade desse mineral para $0,2 \%$, não foram observadas melhoras em relação à porcentagem inicial de fósforo disponível $(0,4 \%)$. Estes resultados podem estar relacionados ao melhor equilíbrio nutricional das dietas experimentais, principalmente considerando-se a relação cálcio e fósforo e aminoacídica, quando se utilizou a quantidade intermediária de fósforo estudado.

Laurentiz et al. (2009) também observaram menor desempenho das aves ao reduzirem o fósforo disponível de 0,41 para $0,17 \%$, utilizando 500 ou 1000FTU de fitase. No entanto, esses autores trabalharam com dietas normais de proteína, ou seja, com $20 \%$. Estes resultados comprovam que a redução excessiva do fósforo, mesmo em dietas contendo fitase, prejudica o desempenho das aves.

Comparando-se as porcentagens de proteína bruta em dietas com diferentes quantidades de fósforo, não foram observadas diferenças $(\mathrm{P}>0,05)$, o que mostra que a inclusão de aminoácidos foi eficiente em assegurar o aporte de aminoácidos essenciais para frangos de corte em dietas com até $14 \%$ de proteína bruta, exceto quando o fósforo está excessivamente reduzido, como mostrado anteriormente.

Ferguson et al. (1998), ao avaliarem a redução de proteína bruta de 20,6 para $18,2 \%$ e do fósforo total de 0,64 para $0,53 \%$ em dietas para frangos em crescimento, não constataram diferenças no desempenho das aves. Rostagno et al. (2002) relataram que a proteína bruta em dietas sem fitase pode ser reduzida até $16 \%$ nesta fase, desde que corrigido o balanço aminoacídico e eletrolítico. Estes valores sugerem um melhor balanço de nutrientes para frangos em crescimento. 
Tabela 2. Desempenho de frangos dos 22 aos 42 dias $(n=20)$ alimentados com dietas contendo proteína bruta e fósforo reduzidos, suplementadas com fitase e aminoácidos

\begin{tabular}{|c|c|c|c|c|c|c|c|}
\hline \multirow{2}{*}{$\begin{array}{l}\text { Proteína } \\
\text { bruta }(\%)\end{array}$} & \multicolumn{3}{|c|}{ Fósforo disponível } & \multirow{2}{*}{ Média } & \multicolumn{3}{|c|}{$\mathrm{P}=$} \\
\hline & $0,2 \%+$ Fitase & $0,3 \%+$ Fitase & $0,4 \%$ & & $\mathrm{~PB}$ & $\mathrm{Pd}$ & $\mathrm{PB} * \mathrm{Pd}$ \\
\hline \multicolumn{8}{|c|}{ Consumo de dieta (kg/ave) } \\
\hline 14 & 3,18 & 3,25 & 3,25 & 3,23 & \multirow{6}{*}{ NS } & \multirow{3}{*}{$<0,05$} & \multirow{3}{*}{ NS } \\
\hline 16 & 3,21 & 3,25 & 3,29 & 3,25 & & & \\
\hline 18 & 3,22 & 3,23 & 3,25 & 3,23 & & & \\
\hline Média & $3,20 b$ & $3,24 \mathrm{a}$ & $3,26 \mathrm{a}$ & & & & \\
\hline Controle & & & 3,28 & & & & \\
\hline \multirow[t]{2}{*}{$\mathrm{CV}(\%)$} & 2,01 & & & & & & \\
\hline & \multicolumn{3}{|c|}{ Ganho de peso (kg/ave) } & & \multirow{6}{*}{ NS } & \multirow{4}{*}{$<0,05$} & \multirow{7}{*}{ NS } \\
\hline 14 & $1,60 *$ & 1,68 & 1,66 & 1,65 & & & \\
\hline 16 & 1,65 & 1,69 & 1,63 & 1,65 & & & \\
\hline 18 & 1,64 & 1,67 & 1,65 & 1,65 & & & \\
\hline Média & $1,63 b$ & $1,68 \mathrm{a}$ & $1,65 b$ & & & & \\
\hline Controle & & & 1,73 & & & \multirow{9}{*}{$<0,05$} & \\
\hline \multirow[t]{2}{*}{$\mathrm{CV}(\%)$} & 3,30 & & & & \multirow{8}{*}{ NS } & & \\
\hline & Conver & alimentar $(\mathrm{kg})$ & & & & & \multirow{7}{*}{ NS } \\
\hline 14 & $1,99^{*}$ & 1,94 & 1,96 & 1,95 & & & \\
\hline 16 & 1,95 & 1,92 & $2,02 *$ & 1,96 & & & \\
\hline 18 & 1,96 & 1,94 & 1,97 & 1,96 & & & \\
\hline Média & $1,96 b$ & $1,93 \mathrm{a}$ & $1,98 b$ & & & & \\
\hline Controle & & & 1,89 & & & & \\
\hline $\mathrm{CV}(\%)$ & 2,86 & & & & & & \\
\hline
\end{tabular}

$\mathrm{PB}=$ proteína bruta; $\mathrm{Pd}=$ fósforo disponível; $\mathrm{NS}=$ não significativo.

Dieta controle: $19 \% \mathrm{~PB}$ e $0,4 \% \mathrm{Pd}$, sem fitase.

*Médias diferem do controle pelo teste Dunnet $(\mathrm{P}<0,05)$.

Médias seguidas por diferentes letras na linha diferem entre si pelo teste $\mathrm{SNK}(\mathrm{P}<0,05)$.

Gomide et al. (2007), avaliando planos nutricionais para frangos de corte, também relataram não haver diferença quando se reduz o nível proteico para $16 \%$ em dietas contendo fitase. Neste caso, o fósforo disponível também foi reduzido para $0,31 \%$, nível semelhante ao avaliado no presente trabalho, mostrando que a fitase é eficiente em liberar o fósforo fítico dos alimentos para o metabolismo dos frangos. Entretanto, resultados controversos podem ser encontrados na literatura, sugerindo que se deve levar em consideração a variabilidade genética dos animais, tipos de alimentos utilizados, condições experimentais e níveis de aminoácidos e enzimas utilizados para compensar a redução da proteína bruta na dieta, já que a fitase pode estar também relacionada à maior disponibilidade destes nutrientes nas dietas (Ravindran et al., 2000).
Com relação às características de carcaça, não foram observadas interações $(\mathrm{P}>0,05)$ em nenhuma das variáveis analisadas (Tab. 3). Comparando-se a dieta-controle com as demais contendo proteína reduzida em diferentes níveis de fósforo contendo ou não fitase, observou-se aumento da gordura abdominal em dietas com $14 \%$ de proteína bruta e níveis reduzidos de fósforo disponível. Segundo Partridge et al. (1985), este resultado pode estar relacionado a um provável desequilíbrio aminoacídico gerado pela adição quantidade excessiva de aminoácidos cristalinos, bem como pela inclusão de fitase, que pode também estar relacionada a esse equilíbrio. A diferença encontrada em dietas com $16 \%$ de proteína bruta e $0,3 \%$ de fósforo disponível não era esperada. 
Tabela 3. Rendimento de carcaça e cortes de frangos $(n=2)$ alimentados com dietas contendo proteína bruta e fósforo reduzidos, suplementadas com fitase e aminoácidos, dos 22 aos 42 dias de idade

\begin{tabular}{|c|c|c|c|c|c|c|c|}
\hline \multirow{2}{*}{$\begin{array}{l}\text { Proteína } \\
\text { bruta (\%) }\end{array}$} & \multicolumn{3}{|c|}{ Fósforo disponível } & \multirow{2}{*}{ Média } & \multicolumn{3}{|c|}{$\mathrm{P}=$} \\
\hline & $0,2 \%+$ Fitase & $0,3 \%+$ Fitas & $0,4 \%$ & & PB & $\mathrm{Pd}$ & $\mathrm{PB} * \mathrm{Pd}$ \\
\hline \multicolumn{8}{|c|}{ Rendimento de carcaça (\%) } \\
\hline 14 & 80,21 & 81,02 & 81,02 & 80,75 & & & \\
\hline 16 & 79,90 & 80,99 & 81,35 & 80,75 & NS & $<0,05$ & NS \\
\hline 18 & 80,55 & 82,49 & 80,56 & 81,20 & & & \\
\hline Média & $80,22 \mathrm{~b}$ & $81,50 \mathrm{a}$ & 80,98 a & & & & \\
\hline Controle & & & 80,43 & & & & \\
\hline \multirow{2}{*}{\multicolumn{8}{|c|}{ Rendimento de peito (\%) }} \\
\hline & & & & & & & \\
\hline 14 & 27,20 & 28,16 & 27,67 & 27,68 & & & \\
\hline 16 & 28,46 & 27,93 & 28,69 & 28,36 & NS & NS & NS \\
\hline 18 & 28,28 & 28,01 & 29,13 & 28,47 & & & \\
\hline Média & 27,98 & 28,03 & 28,50 & & & & \\
\hline Controle & & & 27,64 & & & & \\
\hline \multirow{2}{*}{\multicolumn{8}{|c|}{ Rendimento de coxas e sobrecoxas (\%) }} \\
\hline & & & & & & & \\
\hline 14 & 26,70 & 26,47 & 26,96 & 26,71 & & & \\
\hline 16 & 26,63 & 26,24 & 25,71 & 26,20 & NS & NS & NS \\
\hline 18 & 26,53 & 26,74 & 26,84 & 26,70 & & & \\
\hline Média & 26,62 & 26,48 & 26,50 & & & & \\
\hline Controle & & & 26,66 & & & & \\
\hline $\mathrm{CV}(\%)$ & 3,44 & & & & & & \\
\hline \multicolumn{8}{|c|}{ Rendimento de carne no peito (\%) } \\
\hline 14 & 26,35 & 26,28 & 25,46 & 26,03 & & & \\
\hline 16 & 26,27 & 26,26 & 26,38 & 26,43 & NS & NS & NS \\
\hline 18 & 26,30 & 26,15 & 25,72 & 26,06 & & & \\
\hline Média & 26,31 & 26,36 & 25,85 & & & & \\
\hline Controle & & & 26,50 & & & & \\
\hline \multirow{2}{*}{\multicolumn{8}{|c|}{ Rendimento das asas (\%) }} \\
\hline & & & & & & & \\
\hline 14 & 10,30 & 10,10 & 10,12 & 10,17 & & & \\
\hline 16 & 10,21 & 10,27 & 9,93 & 10,13 & NS & NS & NS \\
\hline 18 & 9,97 & 10,35 & 10,01 & 10,11 & & & \\
\hline Média & 10,16 & 10,24 & 10,02 & & & & \\
\hline Controle & & & 10,13 & & & & \\
\hline \multirow{2}{*}{\multicolumn{8}{|c|}{ Gordura abdominal $(\%)$}} \\
\hline & & & & & & & \\
\hline 14 & $1,61 *$ & $1,63 *$ & 1,38 & $1,54 \mathrm{~A}$ & & & \\
\hline 16 & 1,09 & $1,49^{*}$ & 1,34 & $1,31 \mathrm{~B}$ & $<0,05$ & NS & NS \\
\hline 18 & 0,96 & 1,17 & 1,21 & 1,11B & & & \\
\hline Média & 1,22 & 1,43 & 1,31 & & & & \\
\hline Controle & & & 0,94 & & & & \\
\hline CV (\%) & 25,24 & & & & & & \\
\hline
\end{tabular}

$\mathrm{PB}=$ proteína bruta; $\mathrm{Pd}=$ fósforo disponível; $\mathrm{NS}$ = não significativo.

Dieta controle: $19 \%$ PB e $0,4 \%$ Pd, sem fitase.

*Médias diferem do controle pelo teste Dunnet $(\mathrm{P}<0,05)$.

a,b Médias seguidas por diferentes letras maiúsculas na coluna e minúsculas na linha diferem pelo teste SNK $(\mathrm{P}<0,05)$ 
Mesmo aumentando a gordura abdominal, este resultado não foi suficiente para afetar o rendimento de carcaça $(\mathrm{P}>0,05)$, o que pode ser considerado positivo. Resultados semelhantes foram observados por Costa et al. (2001). Por outro lado, Kerr e Kidd (1999) observaram redução nos rendimentos de carcaça e de peito das aves ao trabalharem com dietas com níveis de proteína bruta variando de 19 a $12 \%$, suplementadas ou não com aminoácidos cristalinos, estando estes resultados associados ao maior rendimento de gordura abdominal. Tais resultados provavelmente podem estar relacionados às diferenças genéticas das aves ou às condições ambientais ou de criação das aves.

Considerando-se as dietas com níveis de proteína bruta reduzidos em diferentes níveis de fósforo, com ou sem fitase, não se observou efeito $(\mathrm{P}>0,05)$ da redução da proteína bruta de 18 para $14 \%$ com inclusão de aminoácidos cristalinos nos rendimentos de carcaça, de cortes e de carne no peito, semelhante ao observado por Araújo et al. (2002). Estes resultados podem estar relacionados à manutenção do metabolismo proteico na massa muscular das aves e à pequena diferença, porém significativa $(\mathrm{P}<0,05)$, na deposição da gordura abdominal em dietas com $14 \%$ de proteína bruta, o que confirma a afirmação de Partridge et al. (1985) de que o excesso de aminoácidos cristalinos eleva a deposição de gordura corporal nos animais. Resultados similares foram observados por Costa et al. (2001), que concluíram que o rendimento de carcaça não foi influenciado pelos níveis de proteína bruta da dieta.

Com relação aos níveis de fósforo em dietas com ou sem fitase, menor rendimento de carcaça foi observado quando a quantidade deste elemento foi reduzida para $0,2 \%$, o que pode estar relacionado ao menor ganho de peso obtido pelas aves neste nível utilizado. Não houve efeito $(\mathrm{P}>0,05)$ da redução dos níveis de fósforo em dietas contendo fitase nas demais características de carcaça avaliadas, resultado semelhante ao obtido por Yonemochi et al. (2003).

Com relação à quantidade de minerais na cama (Tab. 4), observou-se efeito $(\mathrm{P}<0,05)$ da manipulação da dieta na excreção de fósforo, nitrogênio, cálcio, potássio, zinco e cobre. Em relação à dieta controle, a redução do fósforo em dietas contendo fitase diminuiu $(\mathrm{P}<0,05)$ a excreção deste elemento em todos os níveis avaliados, não interferindo na eliminação de nitrogênio, potássio, zinco e cobre. Laurentiz et al. (2009) também não verificaram influência da fitase e níveis de fósforo na dieta de frangos de corte sobre a excreção de zinco, cobre e manganês pelas aves. Quanto à excreção de cálcio, houve redução $(\mathrm{P}<0,05)$ em dietas com $16 \%$ de proteína bruta em relação à dieta controle, provavelmente em função do melhor balanço de nutrientes disponíveis no metabolismo.

Comparando-se as dietas com níveis de proteína bruta reduzidos em diferentes níveis de fósforo contendo ou não fitase, observou-se interação $(\mathrm{P}<0,05)$ apenas com relação ao cálcio. Em dietas com $18 \%$ de proteína bruta, a fitase reduziu $(\mathrm{P}<0,05)$ a excreção de cálcio, independentemente do nível de fósforo disponível utilizado ( 0,2 ou $0,3 \%$ Pd). Já em dietas com $16 \%$ de proteína bruta, a fitase reduziu a excreção de cálcio apenas quando $0,3 \%$ de fósforo disponível foi utilizado, ao passo que, em dietas com $14 \%$ de proteína, o uso da fitase não foi eficiente em reduzir a excreção de cálcio quando $0,3 \%$ de fósforo disponível foi utilizado e piorou quando este último elemento foi reduzido ainda mais $(0,2 \%)$. Estes resultados foram bastante controversos, principalmente devido ao equilíbrio cálcio e fósforo no organismo das aves. Pouco conhecimento se tem da real eficácia da fitase em disponibilizar minerais aos animais. Desta forma, a relação cálcio e fósforo pode ter sido alterada ao se utilizar a enzima em diferentes combinações de alimentos juntamente com aminoácidos cristalinos na dieta.

A redução da proteína bruta diminuiu $(\mathrm{P}<0,05)$ a quantidade de nitrogênio na cama das aves. Apesar de não se observar diferença $(\mathrm{P}>0,05) \mathrm{em}$ relação ao controle para esta variável, é importante salientar que a volatilização da amônia durante o período experimental pode ter influenciado também estes resultados. Além disso, houve diminuição $(\mathrm{P}<0,05)$ do teor de potássio nas camas com a redução da proteína bruta das dietas, provavelmente pela menor porcentagem de farelo de soja na dieta dos animais, que é considerada uma importante fonte deste elemento. A menor excreção de cobre foi obtida com dietas contendo $16 \%$ de proteína bruta. 
Tabela 4. Quantidade de minerais na cama de frangos alimentados com dietas contendo proteína bruta e fósforo reduzidos, suplementadas com fitase e aminoácidos, dos 22 aos 42 dias de idade

\begin{tabular}{|c|c|c|c|c|c|c|c|}
\hline \multirow{2}{*}{$\begin{array}{c}\text { Proteína } \\
\text { bruta }(\%)\end{array}$} & \multicolumn{3}{|c|}{ Fósforo disponível } & \multirow{2}{*}{ Média } & \multicolumn{3}{|c|}{$\mathrm{P}=$} \\
\hline & $0,2 \%+$ Fitase & $0,3 \%+$ Fitase & $0,4 \%$ & & PB & $\mathrm{Pd}$ & $\mathrm{PB} * \mathrm{Pd}$ \\
\hline \multicolumn{8}{|c|}{ Fósforo (\%) } \\
\hline 14 & $1,12 *$ & $1,50^{*}$ & 2,36 & 1,66 & & & \\
\hline 16 & $1,00^{*}$ & $1,58^{*}$ & 2,35 & 1,65 & NS & $<0,05$ & NS \\
\hline 18 & $1,09^{*}$ & $1,60^{*}$ & 2,44 & 1,71 & & & \\
\hline Média & $1,07 \mathrm{c}$ & $1,56 \mathrm{~b}$ & $2,38 \mathrm{a}$ & & & & \\
\hline Controle & & & 2,27 & & & & \\
\hline $\mathrm{CV}(\%)$ & 14,52 & & & & & & \\
\hline \multicolumn{8}{|c|}{ Nitrogênio (\%) } \\
\hline 14 & 2,74 & 2,62 & 2,62 & $2,66 \mathrm{C}$ & & & \\
\hline 16 & 2,90 & 2,87 & 2,90 & $2,89 \mathrm{~B}$ & $<0,05$ & NS & NS \\
\hline 18 & 3,13 & 3,28 & 3,12 & $3,18 \mathrm{~A}$ & & & \\
\hline Média & 2,92 & 2,92 & 2,88 & & & & \\
\hline Controle & & & 3,07 & & & & \\
\hline $\mathrm{CV}(\%)$ & 9,92 & & & & & & \\
\hline \multicolumn{8}{|c|}{ Cálcio (\%) } \\
\hline 14 & $1,17 \mathrm{a}$ & $1,01 \mathrm{~b}$ & $0,94 \mathrm{~b}$ & 1,04 & & & \\
\hline 16 & $0,60 \mathrm{a}^{*}$ & $0,44 b^{*}$ & $0,74 \mathrm{a}^{*}$ & 0,60 & $<0,05$ & $<0,05$ & $<0,05$ \\
\hline 18 & $0,81 \mathrm{~b}$ & $0,89 \mathrm{~b}$ & $1,15 \mathrm{a}$ & 0,95 & & & \\
\hline Média & 0,86 & 0,78 & 0,94 & & & & \\
\hline Controle & & & 1,03 & & & & \\
\hline CV (\%) & 14,68 & & & & & & \\
\hline \multicolumn{8}{|c|}{ Potássio (\%) } \\
\hline 14 & 1,20 & 1,06 & 1,01 & $1,09 \mathrm{~B}$ & & & \\
\hline 16 & 1,31 & 1,23 & 1,23 & $1,25 \mathrm{~A}$ & $<0,05$ & $<0,05$ & NS \\
\hline 18 & 1,39 & 1,29 & 1,27 & $1,32 \mathrm{~A}$ & & & \\
\hline Média & $1,30 \mathrm{a}$ & $1,19 \mathrm{~b}$ & $1,17 \mathrm{~b}$ & & & & \\
\hline Controle & & & 1,20 & & & & \\
\hline CV (\%) & 10,08 & & & & & & \\
\hline \multicolumn{8}{|c|}{ Zinco (ppm) } \\
\hline 14 & 195,79 & 158,63 & 192,28 & 182,23 & & & \\
\hline 16 & 195,50 & 177,68 & 172,10 & 181,74 & NS & $<0,05$ & NS \\
\hline 18 & 226,90 & 197,40 & 174,81 & 199,70 & & & \\
\hline Média & $206,04 a$ & $177,90 \mathrm{~b}$ & $179,72 \mathrm{~b}$ & & & & \\
\hline Controle & & & 186,20 & & & & \\
\hline CV (\%) & 16,95 & & & & & & \\
\hline \multicolumn{8}{|c|}{ Cobre (рpm) } \\
\hline 14 & 34,44 & 36,08 & 34,66 & 35,39A & & & \\
\hline 16 & 25,50 & 26,13 & 26,07 & $25,90 \mathrm{C}$ & $<0,05$ & NS & NS \\
\hline 18 & 28,37 & 28,41 & 30,89 & $29,22 \mathrm{~B}$ & & & \\
\hline Média & 29,77 & 30,20 & 30,58 & & & & \\
\hline Controle & & & 30,96 & & & & \\
\hline CV (\%) & 11,30 & & & & & & \\
\hline
\end{tabular}

$\mathrm{PB}=$ proteína bruta; $\mathrm{Pd}=$ fósforo disponível; $\mathrm{NS}$ = não significativo.

Dieta controle: $19 \%$ PB e $0,4 \%$ Pd, sem fitase.

*Médias diferem do controle pelo teste Dunnet $(\mathrm{P}<0,05)$.

a, b Médias seguidas por diferentes letras maiúsculas na coluna e minúsculas na linha diferem pelo teste SNK $(\mathrm{P}<0,05)$. 
Quanto aos níveis de fósforo, observou-se redução $(\mathrm{P}<0,05)$ da quantidade na cama com a redução deste elemento na dieta, resultado este esperado. No entanto, esta redução na dieta propiciou aumento $(\mathrm{P}>0,05)$ na excreção de potássio e zinco e não interferiu na excreção de nitrogênio e cobre. Resultados semelhantes foram obtidos por Assuena et al. (2009), que verificaram menor excreção de fósforo com a redução deste elemento na dieta suplementada com fitase, mas não observaram efeito desta suplementação na excreção de nitrogênio das aves. Mais estudos devem ser conduzidos visando esclarecer melhor os efeitos da redução da proteína bruta com suplementação de aminoácidos em dietas com fitase para frangos de corte.

\section{CONCLUSÃO}

Os níveis de $14 \%$ de proteína bruta, $0,3 \%$ de fósforo e $0,7 \%$ de cálcio podem ser mantidos em dietas formuladas seguindo o conceito de proteína ideal e suplementadas com fitase para frangos de corte dos 22 aos 42 dias, sem afetar o desempenho e as características de carcaça, porém reduzindo a excreção de fósforo e aumentando a gordura abdominal.

\section{REFERÊNCIAS}

ARAÚJO, C.S.S.; ARTONI, S.M.B.; ARAÚJO, L.F. et al. Desempenho, rendimento de carcaça e excreção de cálcio de frangos de corte, no período de 22 a 42 dias de idade alimentados com diferentes níveis de aminoácidos e cálcio. Rev. Bras. Zootec., v.3, p.2209-2215, 2002.

ASSUENA, V.; JUNQUEIRA, O.M.; DUARTE, K.F. et al. Effect of dietary phytase suplementation on the performance, bone densitometry, and phosphorus and nitrogen excretion of broilers. Rev. Bras. Cienc. Avic., v.11, p.25-30, 2009.

BIEHL, R.R.; BAKER, D.H.; DeLUCA, H.F. 1a-Hydroxylated cholecalciferol compounds act additively with microbial phytase to improve phosphorus, zinc and manganese utilization in chicks fed soy-based diets. J. Nutr., v.125, p.2407-2416, 1995.
COSTA, F.G.P.; ROSTAGNO, H.S.; ALBINO, L.F.T. et al. Níveis dietéticos de proteína bruta para pintos de corte Ross, no período de 1 a 21 dias de idade. REUNIÃO ANUAL DA SOCIEDADE BRASILEIRA DE ZOOTECNIA, 38., 2001, Piracicaba. Anais... Piracicaba, 2001.

FARIA FILHO, D.E.; ROSA, P.S.; VIEIRA, B.S. et al. Protein levels and environmental temperature effects on carcass characteristics, performance, and nitrogen excretion of broiler chickens from 7 to 21 days of age. Rev. Bras. Cienc. Avic., v.7, p.247-253, 2005.

FERGUSON, N.S.; GATES, R.S.; TARABA, J.L. et al. The effect of dietary protein and phosphorus on ammonia concentrate and litter composition in broilers. Poult. Sci., v.77, p.10851093, 1998.

GOMIDE, E.M.; RODRIGUES, P.B.; FREITAS, R.T.F. et al. Planos nutricionais com a utilização de aminoácidos e fitase para frangos de corte mantendo o conceito de proteína ideal nas dietas. Rev. Bras. Zootec., v.36, p.1769-1774, 2007.

KERR, B.J.; KIDD, M.T. Amino acid supplementation of low - protein broiler diets: 1.Glutamic acid and indispensable amino acid supplementation. J. Appl. Poult. Res., v.8, p.298309, 1999.

LAURENTIZ, A.C.; JUNQUEIRA, O.M.; FILARDI, R.S. et al. Desempenho, composição da cama, das tíbias, do fígado e das excretas de frangos de corte alimentados com dietas contendo fitase e baixos níveis de fósforo. Rev. Bras. Zootec., v.38, p.1938-1947, 2009.

PARTRIDGE, I.G.; LOW, A.G.; KEAL, H.D. A note on the effect of feeding frequency on nitrogen use in growing boars given diets with varying levels of free lysine. Anim. Prod., v.40, p.375-377, 1985.

RAVINDRAN, V.; CABAHUG, S.; RAVINDRAN, G. et al. Response of broilers to microbial phytase supplementation as influenced by dietary phytic acid and non-phytate phosphorus levels. II. Effects on nutrient digestibility and retention. Br. Poult. Sci., v.41, p.193-200, 2000.

ROSTAGNO, H.S.; ALBINO, L.F.T.; DONZELE, J.L. et al. Tabelas brasileiras para aves e suínos. Composição de alimentos $e$ exigências nutricionais. Viçosa: UFV, 2000. $141 \mathrm{p}$. 
ROSTAGNO, H.S.; VARGAS Jr., J.G.; ALBINO, L.F.T. et al. Níveis de proteína, eletrólitos e aminoácidos nas rações de frangos de corte na fase de crescimento. In: CONFERÊNCIA APINCO 2002 DE CIÊNCIA E TECNOLOGIA AVÍCOLAS, 2002, Campinas. Anais... Campinas: Associação Brasileira de Produtores de Pinto de Corte, 2002. p.49.

SCHOULTEN, N.A. Níveis de cálcio em dietas para frangos de corte suplementadas com fitase. 2001. 79p. Dissertação (Mestrado em Zootecnia) - Universidade Federal de Lavras. Lavras, MG, Brazil, 2001.

SEBASTIAN, S.; TOUCHBURN, S.P.; CHAVEZ, E.R. Implications of phytic acid and supplemental microbial phytase in poultry nutrition: a review. W. Poult. Sci., v.54, p.27-47, 1998.
SAEG - Sistema de análises estatísticas e genéticas - SAEG. Versão 8.0. Viçosa, MG, 2000. 142p.

YONEMOCHI, C.; FUJISAKI, H.; TAKAGI, H. Effects of amino acid, enzyme mixture and phytase added to low protein and low phosphorus diet on performance and excretion of nitrogen and phosphorus in broilers. Poult. Sci., v.40, p.114-120, 2003. 